\title{
Robust multi-proxy data integration, using late Cretaceous paleotemperature records as a case study
}

\author{
Lineke Woelders $^{\mathrm{a}, \mathrm{b}, *}$, Johan Vellekoop ${ }^{\mathrm{a}}$, Gert Jan Weltje ${ }^{\mathrm{a}}$, Lennart de Nooijer ${ }^{\mathrm{c}}$, \\ Gert-Jan Reichart ${ }^{\mathrm{c}, \mathrm{d}}$, Francien Peterse ${ }^{\mathrm{d}}$, Philippe Claeys ${ }^{\mathrm{e}}$, Robert P. Speijer ${ }^{\mathrm{a}}$ \\ a Division of Geology, Department of Earth and Environmental Sciences, KU Leuven, Celestijnenlaan 200e, 3001 Leuven, Belgium \\ ${ }^{\mathrm{b}}$ Institute of Arctic and Alpine Research, University of Colorado, Boulder, CO, 4001 Discovery Drive, 80303, United States of America \\ c Department of Ocean Systems, NIOZ-Royal Netherlands Institute for Sea Research and Utrecht University, Den Burg, the Netherlands \\ d Department of Earth Sciences, Faculty of Geosciences, Utrecht University, Princetonlaan 8A, 3584 CB, Utrecht, the Netherlands \\ e Analytical, Environmental and Geo-Chemistry, Vrije Universiteit Brussel, Pleinlaan 2, B-1050, Brussels, Belgium
}

\section{A R T I C L E I N F O}

\section{Article history:}

Received 13 March 2018

Received in revised form 2 August 2018

Accepted 4 August 2018

Available online $\mathrm{xxxx}$

Editor: D. Vance

\section{Keywords:}

late Cretaceous

paleotemperature

multi-proxy

data integration

\begin{abstract}
A B S T R A C T
In paleoclimate studies, multiple temperature records are often compared and combined to evaluate temperature trends. Yet, no standardized approach for integrating proxy-derived paleotemperature records exists. In addition, paleotemperature data are often reported without uncertainty estimates (prediction errors), and raw data are not always available. This complicates the quantification of, for example, temperature trends and the magnitude of warming events. Here we propose a robust quantitative approach for multi-proxy analysis in paleoclimate studies. To demonstrate this, we study the latest Maastrichtian warming event (LMWE) in the ODP 174AX Bass River core (New Jersey), and integrate five independent paleotemperature proxies covering the last million years of the Cretaceous. Our integrated temperature reconstruction suggests that, after a climatically stable period, a latest Cretaceous warming of $3.9 \pm 1.1^{\circ} \mathrm{C}$ occurred between $\sim 450$ and $100 \mathrm{kyr}$ before the $\mathrm{K}-\mathrm{Pg}$ boundary. The error on this reconstructed temperature should be considered the absolute minimum error, as poorly constrained or unknown uncertainties cannot be fully propagated. The warming event was followed by a gradual cooling to pre-warming conditions towards the end of the Cretaceous. Furthermore, the record suggests multiple warming pulses during the LMWE. The results of this integrated approach are consistent with other latest Cretaceous temperature records, suggesting that the trend described here represents a global signal.
\end{abstract}

(C) 2018 Elsevier B.V. All rights reserved.

\section{Introduction}

Latest Cretaceous (late Maastrichtian) paleotemperature records suggest a global warming of $2-8{ }^{\circ} \mathrm{C}$ between $\sim 450$ and $\sim 100 \mathrm{kyr}$ before the K-Pg boundary (Li and Keller, 1998; Barrera and Savin, 1999; Olsson et al., 2002; Wilf et al., 2003; Westerhold et al., 2011; Tobin et al., 2012; Petersen et al., 2016; Thibault et al., 2016; Vellekoop et al., 2016; Barnet et al., 2017), possibly as a result of Deccan Traps volcanism (Chenet et al., 2007; Schoene et al., 2015; Henehan et al., 2016). Yet, despite these reports, the exact magnitude of the late Maastrichtian warming event (LMWE) remains poorly constrained, mainly because several sources of uncertainty are not, or are poorly, addressed.

\footnotetext{
* Corresponding author at: Institute of Arctic and Alpine Research, University of Colorado, Boulder, CO, 4001 Discovery Drive, 80303, United States of America.

E-mail address: lineke.woelders@colorado.edu (L. Woelders).
}

Firstly, many, especially older, paleotemperature studies provide proxy records without an analytical error and without providing the raw data in the form of a table or supplementary data file. This introduces a source of uncertainty when using these records in further studies. Though these uncertainty estimates have been included in recent publications on late Cretaceous temperature evolution (Tobin et al., 2012, 2014; Petersen et al., 2016), their absence in older studies limits the accuracy of estimates of the magnitude of the LMWE.

Calibrations used to reconstruct past temperatures introduce a second source of uncertainty. Although they often include a regression error (e.g. Bemis et al., 1998; Lear et al., 2002; Martin et al., 2002; Anand et al., 2003; Kim et al., 2010), this does not provide a realistic estimate of their predictive capabilities as obtained by cross-validation techniques. If the raw data used in temperature calibrations are unavailable, it is impossible to correctly propagate the prediction errors associated with these calibrations, prohibiting accurate estimation of the magnitude of the LMWE. Furthermore, 
lack of access to the raw data does not permit improvement of calibrations by combining different data sets, or by redesigning calibration equations as a result of new insights.

The third source of uncertainty is of a more fundamental nature. The use of modern-day calibrations to reconstruct climatic and environmental changes in the paleo-domain introduces uncertainties whose magnitudes are poorly constrained (or even completely unknown), owing to the fact that parameters of proxy calibrations for temperature estimation cannot be verified for deep-time applications. Modern-day proxy calibrations could be based on species that were nonexistent in the late Cretaceous, and it is not known whether species in this time interval responded similarly to temperature changes as their modern-day counterparts. Detailed information on paleo-sea-water composition (salinity, oxygen isotopes, $\mathrm{Mg} / \mathrm{Ca}$ ratios) is similarly unavailable. Further uncertainty on the magnitude of warming arises from proxy records (Li and Keller, 1998; Barrera and Savin, 1999; Olsson et al., 2002; Tobin et al., 2012) that may have suffered from unknown diagenetic effects (Pearson et al., 2001), which could have altered the original signal. And lastly, each single proxy may also be influenced by variables other than temperature, which prohibits reliable comparison of temperatures derived from different proxies (Lawrence and Woodard, 2017). For example, regional hydrological change as well as the waxing and waning of ice sheets, possibly even in the latest Cretaceous greenhouse climate (Miller et al., 2005), may have influenced late Maastrichtian marine $\delta^{18} \mathrm{O}$ values and thereby reconstructed temperatures.

In addition to these three sources of uncertainty, that prohibit an accurate reconstruction of the LWME, previous late Maastrichtian multi-proxy studies compare temperature records from different locations, rather than comparing multiple proxy records from a single location (Wilf et al., 2003; Woelders et al., 2017). As a result, observed differences between temperature records in these studies could also be caused by, for instance, local diagenetic processes instead of actual (local) climate signals. Furthermore, owing to problems of age constraints (Olsson et al., 2002; Wilf et al., 2003; Woelders et al., 2017), it cannot be excluded that seemingly age-equivalent signals are actually diachronous.

Finally, the low temporal resolution (commonly $<10$ data points in the last million years of the Maastrichtian, Barrera and Savin, 1999; Tobin et al., 2012, 2014; Petersen et al., 2016) and low signal-to-noise ratios (Li and Keller, 1998; Barrera and Savin, 1999; Wilf et al., 2003; Westerhold et al., 2011; Petersen et al., 2016) also limit detailed reconstruction of the LMWE.

The above sources of uncertainty, and additional challenges posed by low resolution datasets and low signal-to-noise ratios, hamper a robust determination of the magnitude of the LMWE, which in turn complicates the assessment of the environmental and ecological implications of late Maastrichtian climate change on the $\mathrm{K}-\mathrm{Pg}$ mass extinction.

The risks associated with relying on single proxy records may be reduced by using multiple paleo-temperature proxy records. Data in multi-proxy studies are commonly displayed side by side to highlight consistency between datasets, or to illustrate patterns of variability unique to each dataset. This approach can, however, be improved upon substantially by statistically integrating temperature records based on different proxies. This enables quantification of the signal shared by the individual datasets (cf. Bloemsma et al., 2012), and allows for more accurate and robust quantification of temperature trends and anomalies. The latter is extremely relevant for climate modeling purposes, as accurate estimates of past sea surface temperatures (SSTs) are a prerequisite for paleoclimate model forcing (e.g. Sloan et al., 2001) and model evaluation (e.g. Otto-Bliesner et al., 2017).

Here we introduce a formal approach to multi-proxy analysis based on data integration, to permit objective assessment of the

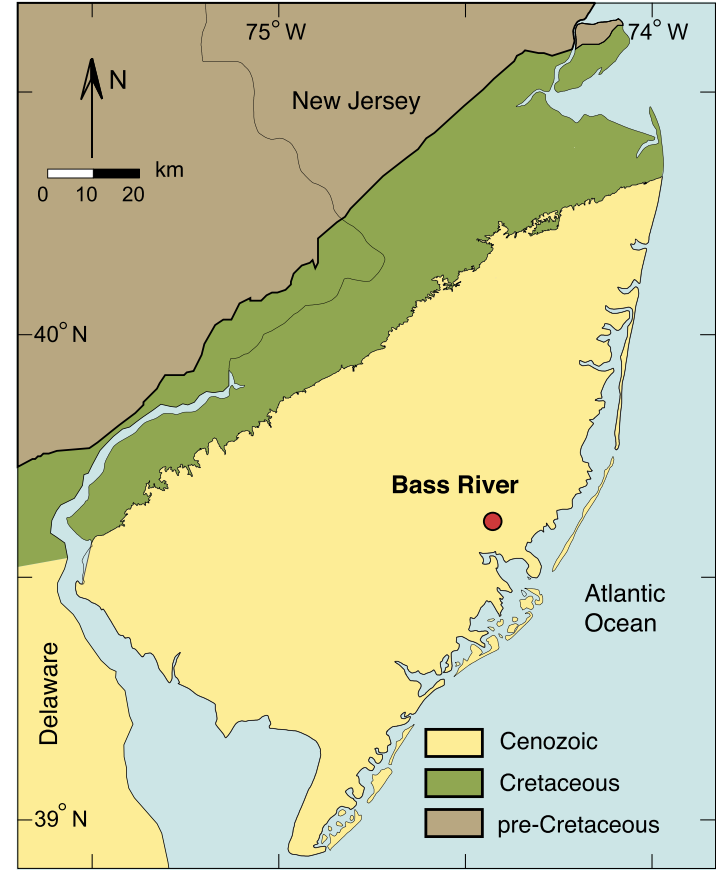

Fig. 1. Geological map of the New Jersey shelf area with the location of ODP Leg 174 AX Bass River site in New Jersey, USA, indicated. Modified after (Esmeray-Senlet et al., 2015). (For interpretation of the colors in the figure(s), the reader is referred to the web version of this article.)

significance of temperature changes. Integration of reconstructed temperature records based on different datasets using different proxies, and thus different temperature calibrations, requires quantification of the uncertainties of each, since the uncertainty directly translates to the weight of evidence of the data and temperature transfer functions. Following this approach, we present an integrated multi-proxy temperature reconstruction of the late Maastrichtian, spanning approximately the last million years of the Cretaceous, by combining benthic and planktic foraminiferal $\delta^{18} \mathrm{O}$ and $\mathrm{Mg} / \mathrm{Ca}$ and the organic geochemical SST proxy $\mathrm{TEX}_{86}$ records for the Bass River core (ODP Leg 174AX, New Jersey, Fig. 1) (Miller et al., 1998; Olsson et al., 2002).

The shelf sequence of Bass River (paleodepth $\sim 100 \mathrm{~m}$, Olsson et al., 2002) comprises an uppermost Maastrichtian record with exceptionally well-preserved benthic and planktic foraminifera (Fig. 2) and biomarker lipids, enabling a multi-proxy temperature reconstruction. The LMWE has previously been identified in the Bass River core, based on stable oxygen isotopes (Olsson et al., 2002; Esmeray-Senlet et al., 2015), indicating that this sedimentary archive is ideal for a case study aimed at testing robust multi-proxy paleo-temperature reconstruction. The glauconite-rich sediments suggest low rates of sediment accumulation, but there is no evidence of the presence of hiatuses in this interval (Miller et al., 1998). Furthermore, despite the limited distance $(\sim 100 \mathrm{~km})$ of the Bass River site to the paleo-coastline (Esmeray-Senlet et al., 2015), the site is directly connected to the open ocean and likely experienced little terrestrial influx (Zachos et al., 2006). This suggests that the site is likely to have recorded the effects of global climate change.

\section{Material and methods}

\subsection{Stable oxygen isotope analysis}

Samples were washed over a sieve with a mesh of $63 \mu \mathrm{m}$ and ultrasonically cleaned. Only specimens from the size fraction of 125-630 $\mu \mathrm{m}$ were analyzed. For benthic $\delta^{18} \mathrm{O}$ analysis, duplicate 


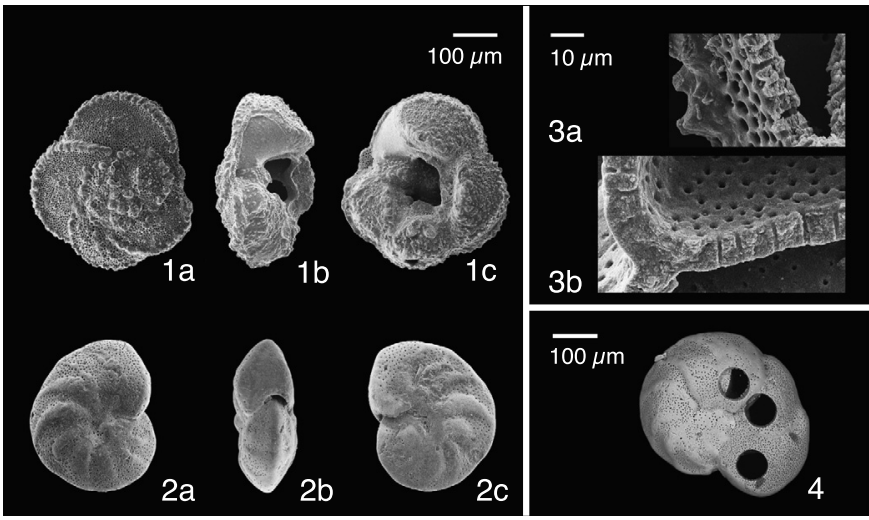

Fig. 2. SEM images of Anomalinoides midwayensis and Globotruncana sp. 1a-c: Globotruncana sp. 2a-c: Anomalinoides midwayensis. 3a: Detail of broken Globotruncana sp. test. 3b: Detail of broken Anomalinoides midwayensis test. 4: Anomalinoides midwayensis with laser holes.

measurements were performed on 7-9 excellently preserved specimens of Anomalinoides midwayensis (Fig. 2) isolated from each of 37 analyzed samples. For planktic $\delta^{18} \mathrm{O}$ analysis, 6-9 specimens of excellently preserved Globotruncana spp. (Fig. 2) were measured from samples containing sufficient specimens. Globotruncana spp. was not sufficiently abundant for adequate $\delta^{18} \mathrm{O}$ analysis in the lowermost samples of the record which is why no data could be generated for this part of the record. Duplicate measurements on Globotruncana spp. could not be performed because of the limited number of well-preserved specimens in each sample. Oxygen stable isotopes were measured with Isotopic Ratio Mass Spectrometry (IRMS) at the Stable Isotope Laboratory of the Analytical, Environmental and Geochemistry research group, Free University of Brussels (VUB). The setup consists of a Perspective IRMS coupled to a NuCarb automated carbonate sampling device (Nu Instruments). Two samples of the in-house standard MAR-2(2), which has been calibrated against the international standard NBS-19 were measured every 8 samples to correct for instrumental drift. Reported values of MAR-2(2) are $0.13 \%$ VPDB for $\delta^{18} \mathrm{O}$ and $3.41 \%$ VPDB for $\delta^{13} \mathrm{C}$. Analytical errors were calculated by the sum of squares of the standard deviations from the individual sample results and the measured MAR-2(2). The weighted mean and corresponding confidence intervals of the benthic dataset were calculated using the method described in Text S1. Data points without analytical error or without a duplicate measurement were assigned an average confidence interval derived from the complete dataset. As no duplicate measurements are available for the planktic dataset, the confidence interval on the planktic data was assumed to be identical to the average confidence interval calculated for the benthic foraminifera.

The temperature transfer function used for benthic foraminifera is that published for Cibicidoides by Marchitto et al. (2014). This function is suitable for relatively warm water conditions and is based on epibenthic Cibicidoides species, which is here considered applicable to Anomalinoides midwayensis, an epibenthic taxon morphologically similar to Cibicidoides. The extinct planktic Globotruncana spp. is presumably a non-symbiotic (D'Hondt and Zachos, 1998) subsurface to thermocline dweller (Abramovich et al., 2003). The temperature transfer function used for Globotruncana spp. is the function for non-symbiotic surface dwelling Globigerina bulloides (13 chambered shell) by Bemis et al. (1998). See also Text $\mathrm{S} 2$. In these calculations, an ice-free world $\delta^{18} \mathrm{O}_{\mathrm{sw}}\left(\delta_{\mathrm{w}}\right)$ value of $-1.2 \%$ was assumed (Shackleton and Kennett, 1975).

To estimate the uncertainty of the predicted temperatures, the standard rules of error propagation were used, using the analytical errors and the uncertainties on the variables in the temperature equations. It should be noted that uncertainty introduced by e.g. unknown seasonality effects, diagenetic effects (despite the careful selection of well-preserved specimens) and by combining several Globotruncana species into Globotruncana spp., could have contributed significantly to the total uncertainty on the reconstructed temperatures (Fraass and Lowery, 2017). These uncertainties were, however, not taken into account, since their quantification is impossible.

\section{2. $\mathrm{Mg} / \mathrm{Ca}$ paleothermometry}

$\mathrm{Mg} / \mathrm{Ca}$ ratios in foraminiferal calcite were used to derive bottom water and sea surface temperatures. Prior to analysis, all foraminiferal tests were cleaned by rinsing with ethanol and ultrasonication, to remove adhering clay and other detrital material. All foraminifera were ultrasonically treated for $30 \mathrm{~s}$ in ethanol. For benthic $\mathrm{Mg} / \mathrm{Ca}$ analysis, 8-12 specimens of $A$. midwayensis were selected for 38 samples. For planktic $\mathrm{Mg} / \mathrm{Ca}$ analysis, 6-12 specimens of Globotruncana spp. (Fig. 2) were selected for 14 samples. Globotruncana spp. was not sufficiently abundant in the lowermost samples of the record for adequate $\mathrm{Mg} / \mathrm{Ca}$ analysis, which is why no data were generated for this part of the record.

We ablated the selected specimens using a NWR193UC (New Wave) that uses an ArF excimer laser with short pulse width and deep-ultraviolet wavelength $(193 \mathrm{~nm})$ (e.g. Reichart et al., 2003). More information on the ablation procedure can be found in Text S3.

For planktic foraminifera, before calculating temperatures from measured $\mathrm{Mg} / \mathrm{Ca}$ values, a $\mathrm{pH}$ correction was applied (using the estimated $\mathrm{pH}$ of past seawater, $\mathrm{pH}_{\mathrm{sw}}$ ). This was not done for benthic foraminifera (Text S3). Furthermore, modern-day temperature calibrations based on $\mathrm{Mg} / \mathrm{Ca}$ values cannot be directly applied to $\mathrm{Mg} / \mathrm{Ca}$ values of foraminifera that lived in oceans with a considerably different $\mathrm{Mg} / \mathrm{Ca}$. Therefore, the measured $\mathrm{Mg} / \mathrm{Ca}$ values were transformed to modern-day values before the calibrations were applied. This transformation was done by applying a correction for the difference between past $\mathrm{Mg} / \mathrm{Ca}_{\text {sw }}$ and present seawater $\mathrm{Mg} / \mathrm{Ca}$ $\left(\mathrm{Mg} / \mathrm{Ca}_{\text {sw,present }}\right)$ (Text S3). For this transformation, a $\mathrm{Mg} / \mathrm{Ca}_{\text {sw }}$ value of $1.25 \mathrm{~mol} / \mathrm{mol}$ during the latest Cretaceous as reconstructed by Stanley and Hardie (1998) was assumed. The assumed $\mathrm{Mg} / \mathrm{Ca}_{\mathrm{sw}}$ and $\mathrm{pH}_{\mathrm{sw}}$ are associated with uncertainties, potentially influencing the reconstructed temperatures. Despite the fact that these uncertainties can be considerable (Text S3), they only result in a linear transformation of absolute temperature reconstructions. Relative temperature changes are not affected by these uncertainties.

The temperature transfer function used for benthic foraminifera is the function for Cibicidoides from Lear et al. (2002) which is suitable for relatively warm water conditions. Epibenthic Cibicidoides morphologically resembles extinct epibenthic taxon Anomalinoides midwayensis used in this study. For extinct planktic Globotruncana spp., we use the $\mathrm{Mg} / \mathrm{Ca}$ (Lea et al., 1999) transfer function based on non-symbiont bearing Globigerina bulloides. See also Text S3.

To estimate uncertainties for the predicted temperatures, the standard rules of error propagation were used, using the analytical errors and the uncertainties on the variables in the temperature equations. See also Text S3. As with stable oxygen isotope analysis, uncertainties resulting from e.g. unknown seasonality effects, undetected diagenetic overprint or combining the individual Globotruncana species in the Globotruncana spp. group could not be quantified.

\section{3. $T E X_{86}$ paleothermometry}

For $\mathrm{TEX}_{86}$ analyses, freeze-dried, powdered samples $(\sim 10 \mathrm{~g}$ dry mass) were extracted with an accelerated solvent extractor using a 9:1 (vol/vol) dichloromethane (DCM):methanol solvent mixture. The obtained extracts were separated over an acti- 


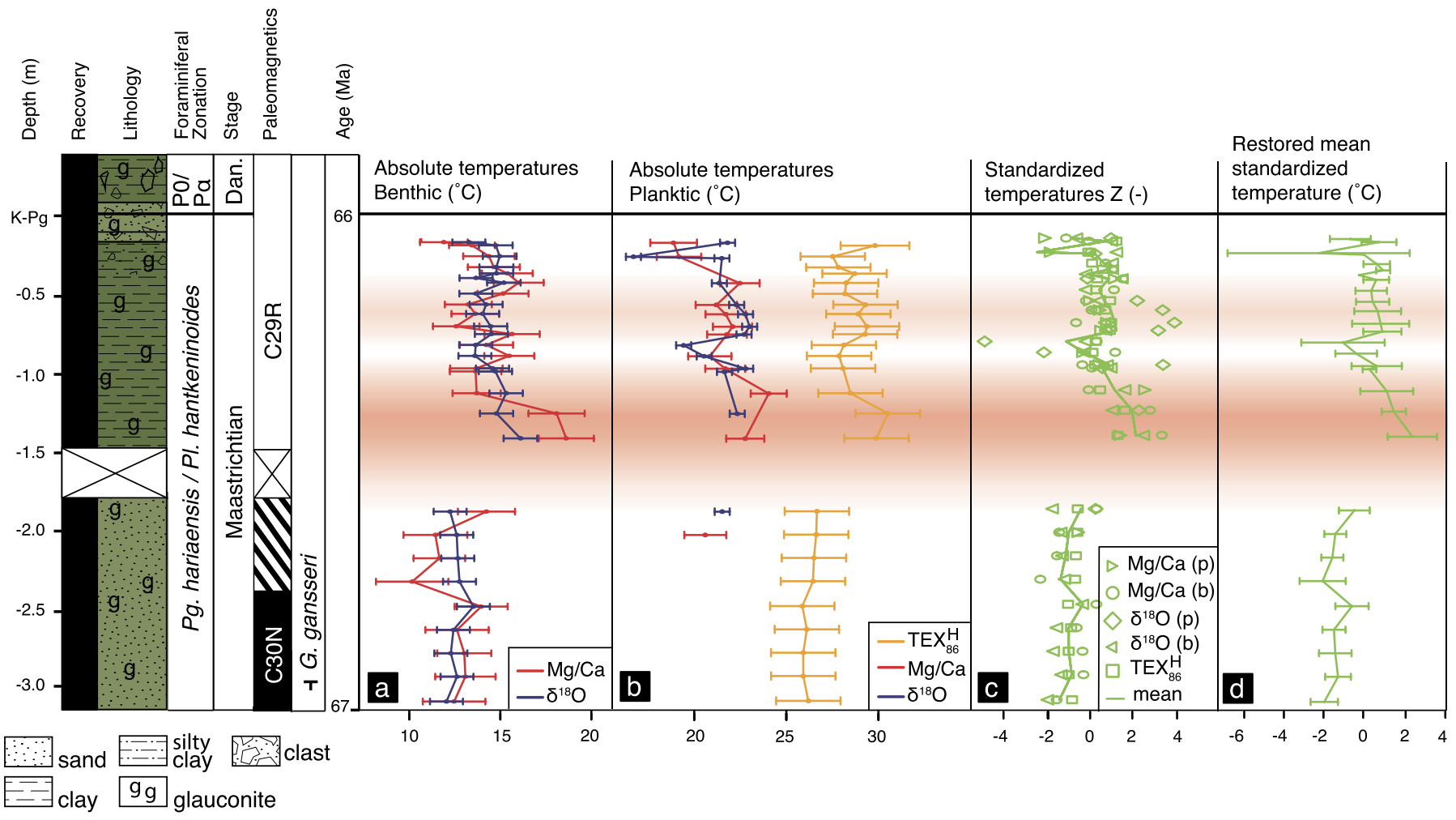

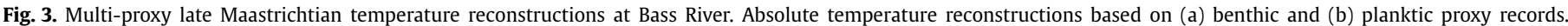

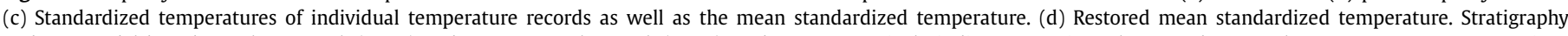

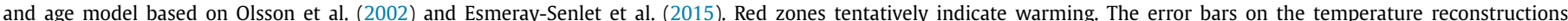

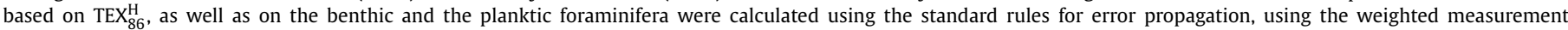

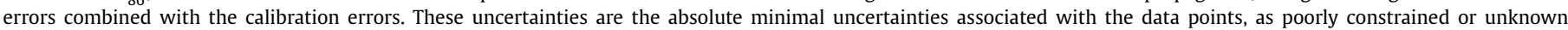
uncertainties cannot be fully propagated.

vated $\mathrm{Al}_{2} \mathrm{O}_{3}$ column, using 9:1 (vol/vol) hexane: DCM, ethyl acetate (100\%), 95:5 (vol/vol) DCM:MeOH, and 1:1 (vol/vol) DCM: methanol, into apolar, ethylacetate, tetraether, and polar fractions, respectively. The tetraether fractions, containing the glycerol dialkyl glycerol tetraethers (GDGTs) used for the $\mathrm{TEX}_{86}$ index were analyzed in duplicate by high performance liquid chromatography/atmospheric pressure positive ion chemical ionization-mass spectrometry (HPLC/APCI-MS) using an Agilent 1260 Infinity ultra HPLC coupled to an Agilent 6130 single quadrupole MS, following the elution scheme of Hopmans et al. (2016).

The $\mathrm{TEX}_{86}^{\mathrm{H}}$ calibration from Kim et al. (2010) is the most commonly used transfer function for deep-time (pre-Neogene), extrapolar greenhouse conditions (Schouten et al., 2013). Therefore, in this study, TEX $_{86}$ index values were calculated for the duplicate measurements and in principal converted into SSTs using the $\mathrm{TEX}_{86}^{\mathrm{H}}$ calibration from Kim et al. (2010). Later (section 4.3) we discuss this choice of the empirical $\mathrm{TEX}_{86}^{\mathrm{H}}$ calibration for our $\mathrm{TEX}_{86}$ data from the data-sparse, latest Cretaceous greenhouse over the statistically better constrained BAYSPAR calibration (Tierney and Tingley, 2014). Additional information on the quality control of the data can be found in Text S4. The weighted mean of the duplicate temperature estimate and the corresponding confidence intervals were calculated using the method described in Text S1. The uncertainty on the reconstructed temperatures is $\pm 2.5^{\circ} \mathrm{C}$.

\subsection{Calculation of the weighted mean and inverted $\mathrm{Chi}^{2}$ fitting}

We introduce a formal approach to multi-proxy analysis based on data integration, which permits an objective assessment of the significance of temperature changes. In order to integrate the five proxy records, we standardize each based on uncertainties of the individual data points as well as their scatter around the weighted mean of the individual records (Inverted chi-squared fitting and $\mathrm{Z}$ score analysis, see Text S1). The uncertainties of the individual data points are obtained by propagating analytical errors as well as the regression errors on the calibrations used. As such, these uncertainties are the absolute minimal uncertainties associated with the data points, as poorly constrained or unknown uncertainties cannot be fully propagated. The $\mathrm{Z}$ score analysis is needed because late Maastrichtian temperature has been reconstructed using different methods, and an integrated estimate can only be obtained by centering the individual temperature records on zero to eliminate systematic errors that are inherent to paleo-temperature estimates ( $\mathrm{Z}$ score analysis, Text $\mathrm{S} 1$ ). After the quantitative integration of temperature records, the range of the mean standardized temperature record is restored. The uncertainty around the restored mean standardized temperature is restored by an inverse scaling operation (see Text S1). The magnitude of the LMWE is estimated by determining the difference between the weighted mean of the restored standardized temperatures in the relatively stable interval below the warming $(-3.11$ to $-1.45 \mathrm{~m}$ ) and the weighted mean of the data points of the restored standardized temperatures with higher temperatures in the warming interval.

As intense bioturbation resulted in mixing of Paleocene sediments with the uppermost $15 \mathrm{~cm}$ of the Maastrichtian (Olsson et al., 1997), measurements from this interval have not been used to calculate the weighted mean of the proxy records.

\section{Results}

\subsection{Latest Cretaceous climate change}

The late Maastrichtian temperature reconstructions from Bass River show similar trends (Fig. 3a and $3 b$ ). All proxies indicate 


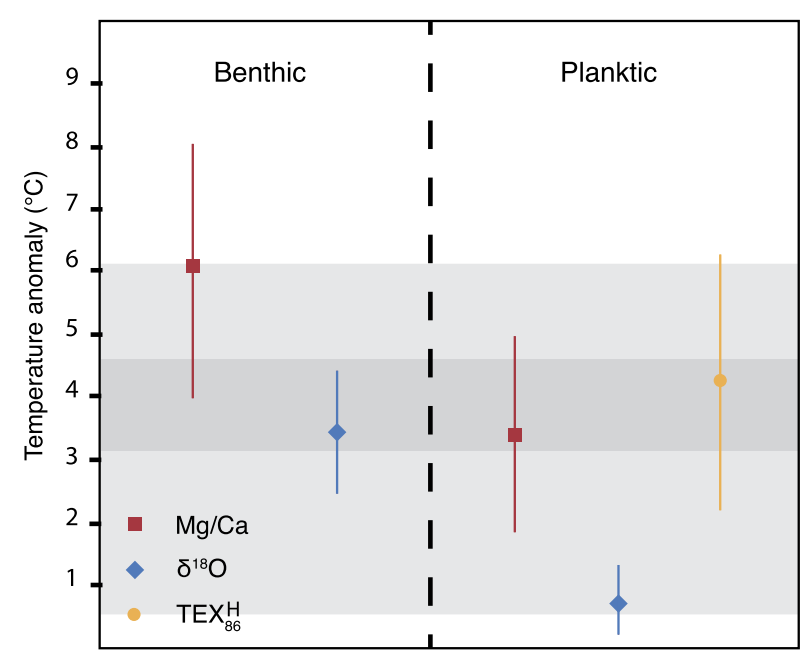

Fig. 4. Magnitude of the temperature anomaly during the LMWE for the different proxy-based temperature records of Bass River. Dark gray area: weighted mean average of the LMWE from benthic and planktic $\mathrm{Mg} / \mathrm{Ca}$, benthic $\delta^{18} \mathrm{O}$ and $\mathrm{TEX}_{86}$-based temperature reconstructions (alternative approach, see section 4.1). Light gray area: integrated multi-proxy estimation of the LMWE (section 2.4).

an interval with relatively stable temperatures from $\sim 3.11 \mathrm{~m}$ up to $\sim 1.45 \mathrm{~m}$ below the K-Pg boundary. Between 1.42 and $1.13 \mathrm{~m}$ below the boundary, a warming relative to the stable interval is indicated by all temperature proxies. The simultaneous occurrence of the warming interval in the individual temperature records suggests that bottom and (sub)surface waters warmed simultaneously. The approach of data integration as described in Methods (2.4) results in an estimate of late Maastrichtian warming of $3.3 \pm 2.8^{\circ} \mathrm{C}$ (light-gray area in Fig. 4).

It is impossible to pinpoint the exact timing of the onset of the LMWE because of the lack of detailed biostratigraphy and the presence of a core gap (Miller et al., 1998) (Fig. 3). Given these limitations, the timing of the warming interval recorded in Bass River (between $\sim 450$ and $\sim 100$ kyr before the K-Pg boundary, with peak warming at $\sim 250 \mathrm{kyr}$ before the $\mathrm{K}-\mathrm{Pg}$ boundary) was estimated based on paleotemperature records with better age constraints (Li and Keller, 1998; Barrera and Savin, 1999; Wilf et al., 2003; Westerhold et al., 2011; Tobin et al., 2012; Petersen et al., 2016; Vellekoop et al., 2016; Barnet et al., 2017; Woelders et al., 2017).

Above the warming peak between -1.42 and $-1.13 \mathrm{~m}$, all proxies suggest a cooler interval before the K-Pg boundary. However, temperatures remain relatively high up to $0.50 \mathrm{~m}$ below the boundary. Although the absence of stratigraphic markers in this part of the core prevents an accurate age estimate, the onset of this cooling likely corresponds to an age of $\sim 100 \mathrm{kyr}$ before the $\mathrm{K}-\mathrm{Pg}$ boundary (Barnet et al., 2017). Between $\sim-0.75$ to $-0.50 \mathrm{~m}$ below the boundary, the planktic proxy-based temperature reconstructions suggest a second, less intense, warming event (Fig. 3b), although not statistically significant. Data can be found in Supplementary Data Files Dataset S1-S3.

\section{Discussion}

\subsection{Unknown and unquantified uncertainties}

In this study, the error budget for each reconstructed temperature record was set up to be as inclusive and realistic as possible. Yet, it should be noted that despite this effort, it is impossible to include all possible sources of error and uncertainty, since some of these sources are unknown or poorly constrained.

For example, the input of low salinity waters from runoff on the near-shore location of the studied site could have changed un- der influence of a changing climate, and this could in turn have affected stable oxygen isotopic values. Similarly, unknown diagenetic effects could have influenced proxy values. Yet, since there is no evidence for changes in fresh water inputs near the studied site, nor for diagenetic effects, it is impossible to quantify this kind of unknown uncertainty.

But even if there is some (poor) constraint on a source of uncertainty, it is not recommended to include this source in the uncertainty budget. An example of poorly constrained uncertainty possibly affecting the outcome of the reconstructions in this study is the assumed constant atmospheric $\mathrm{CO}_{2}$ concentration over the studied interval. A stable atmospheric $\mathrm{CO}_{2}$ level, and thus seawater $\mathrm{pH}$, throughout the late Maastrichtian was assumed in this study. $\mathrm{CO}_{2}$ and concurrently seawater $\mathrm{pH}$ may, however, have changed during this interval, which may possibly have influenced proxy values.

But few estimates of changing $\mathrm{pCO}_{2}$ during the LMWE are available, and these estimates are mostly highly uncertain and/or based on records with low temporal resolution. Nordt et al. (2003), for instance, estimated a change in atmospheric $\mathrm{CO}_{2}$ of $\sim 600$ to $\sim 1400 \mathrm{ppm}$ during the LMWE using oxygen and carbon isotopic ratios (based on only one measurement value in the warming interval). Henehan et al. (2016) estimate that atmospheric $\mathrm{CO}_{2}$ may have changed from $\sim 600 \mathrm{ppm}$ to max. $\sim 700 \mathrm{ppm}$, or could have changed as much as from $\sim 600 \mathrm{ppm}$ to $\sim 1300 \mathrm{ppm}$ during the warming interval. An increase in $\mathrm{pCO}_{2}$ from 600 to $700 \mathrm{ppm}$ would result in a decrease in seawater $\mathrm{pH}$ from $\sim 8.1$ to $\sim 8.0$ (0.1 pH units) (Zeebe, 2001). A $\sim 600$ to $\sim 1300$ increase would result in a decrease in seawater $\mathrm{pH}$ from $\sim 8.1$ to $\sim 7.7$ ( $0.4 \mathrm{pH}$ units).

Benthic foraminiferal $\mathrm{Mg} / \mathrm{Ca}$ does not seem sensitive to changes in $\mathrm{pH}$ (Supplementary Information). Some authors show an insignificant change in $\mathrm{Mg} / \mathrm{Ca}$ over the applied range in $\mathrm{pH}$ 's (e.g. Kisakürek et al., 2008). Other authors report a modest effect of $\mathrm{pH}$ on planktic foraminiferal $\mathrm{Mg} / \mathrm{Ca}$ in some species (Lea et al., 1999; Russell et al., 2004). Assuming that the equation for O. universa from Russell et al. (2004) represents the maximum effect of $\mathrm{pH}$ on $\mathrm{Mg}$ incorporation, a $\mathrm{pH}$ variability of 0.1 unit would result in a maximum variability in $\mathrm{Mg} / \mathrm{Ca}$ of $0.6 \mathrm{mmol} / \mathrm{mol}$, irrespective of the absolute $\mathrm{Mg} / \mathrm{Ca}$ values. With a planktic $\mathrm{Mg} / \mathrm{Ca}$ of $\sim 4.6$, the reconstructed temperature would be associated with an additional maximum uncertainty of $\sim 1{ }^{\circ} \mathrm{C}$ (Lea et al., 1999).

The relationships between $\delta^{18} \mathrm{O}$, atmospheric $\mathrm{CO}_{2}$ and sea water carbonate chemistry are reasonably well established (Zeebe, 2001 ), and potential variations are more pronounced. If atmospheric $\mathrm{CO}_{2}$ would have changed from 600 to $700 \mathrm{ppm}$ during the LMWE, corresponding to a change in ocean $\mathrm{pH}$ of $0.1 \mathrm{pH}$ unit, this would result in a modest apparent shift in $\delta^{18} \mathrm{O}$-based seawater temperature of $0.7^{\circ} \mathrm{C}$ (Zeebe, 2001). An increase from $\sim 600$ to $\sim 1400 \mathrm{ppm}(0.4 \mathrm{pH}$ units $)$ would result in a relatively large apparent temperature shift of $2.7^{\circ} \mathrm{C}$.

As there always are poorly constrained factors influencing the outcome of any reconstruction, this would imply that reconstructing any paleoenvironmental variable would simply be impossible, as the uncertainty would become much larger than the reconstructed signal. It is therefore recommended to only include wellconstrained uncertainties in the error budget, and to be aware of the fact that the calculated uncertainty on a reconstructed variable is always merely a minimum value. Error budgets may improve if these poorly constrained factors become better understood, permitting them to be included in the approach advocated here.

The use of multiple proxies in paleo-reconstructions is strongly recommended, if only because different proxies respond differently to potential unknown or unquantified factors. If individual reconstructions in a multi-proxy reconstruction are in agreement, this implies that they are most likely not severely influenced by unknown or unquantified factors. Multi-proxy studies, therefore, also 


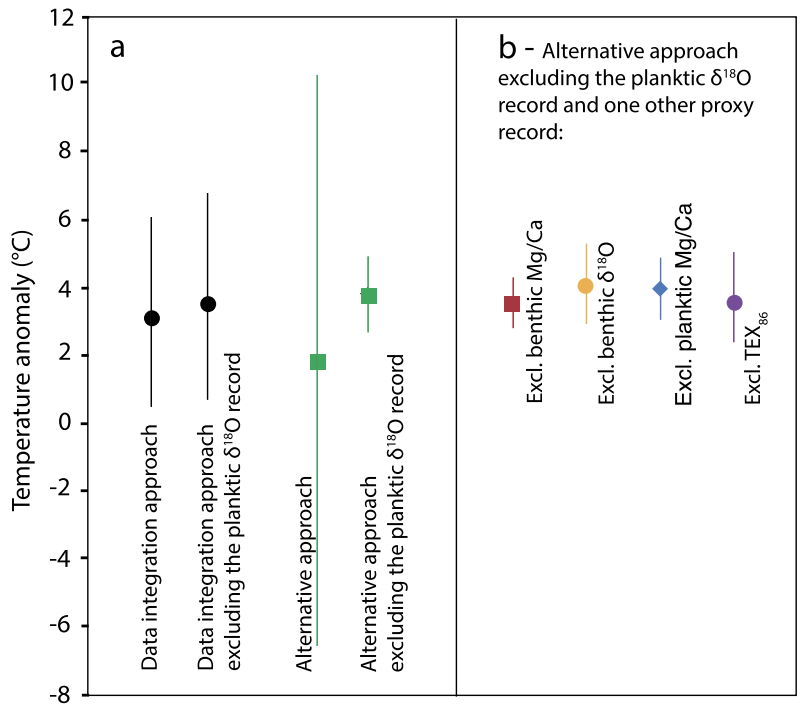

Fig. 5. (a) Magnitude of LMWE $\left({ }^{\circ} \mathrm{C}\right)$ reconstructed using the formal approach as described in Methods (2.4) and the alternative approach described in section 4.1, with and without inclusion of the planktic $\delta^{18} \mathrm{O}$ record. (b) Reconstruction using the alternative approach, excluding one additional proxy record from the analysis.

contribute to a better understanding of deviations among individual proxy records.

\subsection{Magnitude of late Maastrichtian warming at Bass River}

Our approach of data integration results in an estimate of late Maastrichtian warming of $3.3 \pm 2.8^{\circ} \mathrm{C}$ (light gray zone in Fig. 4; Fig. 5a), where the error on this reconstructed temperature is the absolute minimum error, as poorly constrained or unknown uncertainties cannot be fully propagated. There are several reasons for this relatively large uncertainty. Firstly, the stratigraphic position of the temperature changes in the warming interval differs between the individual temperature records (Fig. 3). This means, for instance, that the maximum temperature may occur at slightly different depths for each individual record. Such differences may have been caused by secondary processes such as reworking, diagenesis and leaching, which may have distorted the original signals of the different individual proxies. When the different records are then combined using the data integration approach, where data from the same stratigraphic position are combined, this may result in large uncertainty. Secondly, not all individual proxy records, and corresponding late Maastrichtian warming magnitudes, are in agreement. For instance, the rather modest planktic $\delta^{18} \mathrm{O}$-based late Maastrichtian warming magnitude of $0.8 \pm 0.6{ }^{\circ} \mathrm{C}$ is not supported by the other proxy records (Fig. 3 ). This is likely the result of an overall lack of pre-warming planktic data in the record. When the data from deviating records are included in the integration, this results in a large uncertainty. Thirdly, including a record that has large uncertainty, such as the $\mathrm{TEX}_{86}$-based temperature record (Fig. 3), results in a higher uncertainty for the integrated temperature record. Finally, this approach can only be applied if proxy data of the exact same age (depth) are available. Although this is the case for the Bass River core, this may not be the case for most multi-proxy records.

To circumvent this problem and reduce aforementioned uncertainties, the magnitude of the LMWE can also be estimated for each individual record by calculating the difference between the weighted mean of the reconstructed temperatures in the prewarming interval $(-3.11$ to $-1.45 \mathrm{~m})$ and the maximum temperature in the warming interval (Fig. 4). In this approach, the maximum temperature does not necessarily occur at the same depth for every record (Fig. 3). In the benthic $\mathrm{Mg} / \mathrm{Ca}$ record, maximum warming occurs at -1.42 and $-1.26 \mathrm{~m}$ depth, in the planktic $\mathrm{Mg} / \mathrm{Ca}$ record at $-1.13 \mathrm{~m}$ depth, in the benthic $\delta^{18} \mathrm{O}$ record at $-1.42,-1.26$ and $-1.13 \mathrm{~m}$ depth, and in the planktic $\delta^{18} \mathrm{O}$ record and the $\mathrm{TEX}_{86}$ record at $-1.26 \mathrm{~m}$ depth. Subsequently, the weighted mean of the calculated warming magnitude of the individual records can be calculated in an alternative approach. The application of this alternative approach, even when data from the same depth are available, is justified by the fact that aforementioned secondary processes may have distorted the original signals of the different individual proxies. It is stressed, however, that this alternative approach should be used with more caution than the robust technique discussed above, and its performance should be judged in the light of the outcome of the robust technique.

When this alternative approach is applied to the entire proxy dataset of Bass River, a warming of $1.9 \pm 8.3^{\circ} \mathrm{C}$ is indicated (Fig. 5a). The large uncertainty of this reconstructed warming magnitude does not allow us to establish whether or not a warming occurred during this interval.

Excluding strongly deviating records from data integration during this step of the alternative approach reduces uncertainty significantly. For instance, since the pre-warming interval for the planktic $\delta^{18} \mathrm{O}$-based temperature record consists of only one data point, due to the rarity of the investigated planktic foraminiferal species below this level, accurately reconstructing a temperature anomaly for this proxy record is not feasible. Moreover, other, unconstrained (i.e. without uncertainty estimate) planktic $\delta^{18} \mathrm{O}$ records from Bass River from this interval indicate a 0.5 to $1.0 \%$ shift in planktic $\delta^{18} \mathrm{O}$ values during this interval, corresponding to a $\sim 2.5$ to $\sim 4.5^{\circ} \mathrm{C}$ temperature increase (Olsson et al., 2002; Esmeray-Senlet et al., 2015). Disregarding the entire planktic $\delta^{18} \mathrm{O}$ record is therefore considered a reasonable decision in this alternative approach. In Fig. 5a, it is demonstrated that eliminating the planktic $\delta^{18} \mathrm{O}$ record strongly decreases the uncertainty on the estimated late Maastrichtian warming magnitude. Fig. 5b furthermore shows that eliminating an additional proxy record from the alternative data integration process does not reduce uncertainty significantly, indicating that the other proxy records are in agreement.

Although this pragmatic, alternative approach is less robust than the formal integrated method, which does not change significantly after omitting the planktic $\delta^{18} \mathrm{O}$ record (Fig. 5a), it allows for a qualitative assessment of the individual temperature reconstructions. The weighted mean of the four proxy records combined (without the planktic $\delta^{18} \mathrm{O}$ record) suggests a late Maastrichtian warming magnitude of $3.9 \pm 1.1^{\circ} \mathrm{C}$ (Fig. 5a; dark gray zone in Fig. 4). This estimate is in good agreement with the formal, robust, integrated estimate of the LMWE of $3.3 \pm 2.8^{\circ} \mathrm{C}$, although with considerably smaller uncertainty. In addition, the pragmatic alternative approach allows for the integration of temperature records that are not derived from the exact same stratigraphic depth and/or location, which is useful in case these are not available.

\subsection{Evaluating the robustness of absolute and relative reconstructed temperatures}

Although all proxy records display similar trends, the reconstructed absolute bottom and surface water temperatures differ from each other (Fig. 3). This observed gradient is in line with the paleohydrographic reconstruction for Bass River by Esmeray-Senlet et al. (2015). Yet, it is possible that the application of modern transfer functions to extinct organisms in deep time resulted in deviating reconstructed absolute temperatures, which may explain the difference between the absolute $\mathrm{TEX}_{86}^{\mathrm{H}}$ and planktic foraminiferal temperature curves. 
The transfer functions that are used to reconstruct temperatures from proxy data are not calibrated for deep-time time intervals, with environmental conditions that are different from those of today, or for extinct (foraminiferal) species. This introduces an unconstrained uncertainty in the reconstructed temperatures, which is not necessarily a simple linear transformation of the calculated temperatures as is the case with the used $\mathrm{pH}$ and $\mathrm{Mg} / \mathrm{Ca}_{\mathrm{sw}}$ corrections (see Text S3). The uncertainties regarding the transfer functions used thus affect absolute as well as relative temperatures. Moreover, the uncertainties of individual transfer functions can differ from each other. Using different transfer functions for the same proxy data can substantially impact reconstructed absolute temperatures.

For example, the extinct, non-symbiont bearing Globotruncana spp. (D'Hondt and Zachos, 1998) used in the Bass River analysis presumably was a subsurface to intermediate water dweller (Abramovich et al., 2003). Therefore, the use of a $\mathrm{Mg} / \mathrm{Ca}$-based transfer function for the surface dweller Globigerina bulloides, as done here, is not the most obvious choice, especially since transfer functions based on deeper dwelling taxa such as Globorotalia truncatulinoides are also available (e.g. Anand et al., 2003). Yet, temperatures reconstructed using the functions based on Globorotalia truncatulinoides yield temperatures that are too high to be realistic, $>10^{\circ} \mathrm{C}$ higher than planktic $\delta^{18} \mathrm{O}$-based reconstructed temperatures and $>5^{\circ} \mathrm{C}$ higher than $\mathrm{TEX}_{86}$-based reconstructed temperatures. Although it should be noted that this offset could partially be caused by the chosen $\mathrm{pH}$ and $\mathrm{Mg} / \mathrm{Ca}_{\mathrm{sw}}$ values, it is unlikely that an offset of this magnitude is solely caused by the choice of these parameters.

The $\delta^{18} \mathrm{O}$-based temperature transfer function used for Globotruncana spp. is the function for non-symbiotic surface dwelling Globigerina bulloides (13 chambered shell) by Bemis et al. (1998), since no transfer functions that are explicitly designed for subsurface or thermocline dwelling planktic foraminifera are available. However, this choice of transfer function most likely results in absolute reconstructed temperatures that are offset.

For $\mathrm{TEX}_{86}$-based temperature reconstructions, a spatially-varying relationship between TEX $_{86}$ and SSTs was recently suggested (Kim et al., 2010; Tierney and Tingley, 2014). This resulted in the development of BAYSPAR, a Bayesian regression approach to the TEX ${ }_{86}-$ SST calibration that explicitly allows for model parameters to smoothly vary as a function of space (Tierney and Tingley, 2014). This is an excellent alternative approach for reconstructing temperatures from $\mathrm{TEX}_{86}$ values in more recent times (i.e. Neogene and Quaternary), where $\mathrm{TEX}_{86}$ data are both spatially as well as temporally abundant. However, in deep-time, such as the latest Cretaceous, data are sparse, which reduces the value of the approach embodied in BAYSPAR. The decision to reconstruct paleotemperatures based on the relation between measured $\mathrm{TEX}_{86}^{\mathrm{H}}$ and the corresponding range of temperatures in the modern-day data results in a large uncertainty of temperatures reconstructed using this method for deep-time intervals compared to other methods (Fig. S6). In addition, TEX $\mathrm{H}_{86}^{\mathrm{H}}$ is a non-linear model, whereas BAYSPAR is a linear model. For the modern ocean, the two models result in comparable SSTs. However, for the high end of the TEXSST relationship, BAYSPAR results in higher SSTs than with $\mathrm{TEX}_{86}^{\mathrm{H}}$ (Fig. S6).

Recent mesocosm experiments indicate that the $\mathrm{TEX}_{86}$ index does not systematically respond to temperature change for all Thaumarchaeal strains (Elling et al., 2015). Instead, the change in temperature is better captured by the Ring Index, which, in contrast to $\mathrm{TEX}_{86}$, includes GDGT-0 and crenarchaeol. The ratio of GDGT-0 versus TEX $_{86}$ for the global core top calibration of Kim et al. (2010; cf. Cramwinckel et al., 2018) shows a strongly nonlinear relation, indicating that at high temperatures the response of the GDGTs included in the $\mathrm{TEX}_{86}$ index to temperature change is limited compared to that of GDGT-0 and crenarchaeol. This suggests that the flattening of the relation between $\mathrm{TEX}_{86}$ and SST at high temperatures is not only a consequence of regression dilution (Tierney and Tingley, 2014) but also a true biophysical mechanism. Hence, we prefer to use a non-linear function to reconstruct SSTs for our latest Cretaceous dataset. Nevertheless, absolute SST values obtained from the extrapolated part of the calibration should always be interpreted with caution. However, trends, timing, and the direction of changes in GDGT-based SST records are reliable and independent of the calibration used.

The effect of using different transfer functions on absolute temperature reconstructions as well as on temperature anomalies (the LMWE) was tested by applying several different transfer functions to each proxy dataset. For an overview of the differences in absolute temperature reconstructions and temperature changes, using different calibrations and transfer functions, amongst others using the BAYSPAR calibration (Tierney and Tingley, 2014) versus the $\mathrm{TEX}_{86}^{\mathrm{H}}$ calibration, see Figs. S2-S6. The use of different transfer functions indeed often results in significantly deviating absolute temperatures. Yet, the calculated late Maastrichtian temperature anomalies (calculated using the alternative approach, see section 4.1) using different transfer functions are similar (Figs. S2-S6). We therefore argue that calculated temperature changes are far less sensitive to the choice of transfer function, and therefore more reliable than absolute temperatures in deep-time studies.

\subsection{Intercomparison of the individual proxy records at Bass River}

Comparing the calculated magnitude of warming from individual records in a multi-proxy study can provide insight into whether or not these proxies were likely influenced by other factors besides temperature. For instance, large reductions in the size of ice sheets results in more negative seawater $\delta^{18} \mathrm{O}$ values. Therefore, $\delta^{18} \mathrm{O}$ records during periods of major ice melt would yield higher reconstructed temperatures compared to other temperature reconstructions. If substantial ice sheets had been present on Antarctica during the latest Cretaceous, as suggested by Miller et al. (2005), they likely would have disappeared or significantly been reduced during the LMWE. The input of ice sheet melt water would in turn have led to lower seawater $\delta^{18} \mathrm{O}$ values, which would result in an overestimation of the LMWE reconstructed from foraminiferal $\delta^{18} \mathrm{O}$-based temperatures. Yet, the amplitude of the warming reflected by $\delta^{18} \mathrm{O}$-based temperature reconstructions is similar to that of the other proxies in the same interval (Fig. 3, Fig. 4). Hence, our data do not suggest that a significant ice sheet was present on Antarctica during the latest Cretaceous, although we cannot exclude the possibility of a minor ice-sheet melting signal, as this may well be obscured by the effects of local circulation patterns and/or hydrological changes.

\subsection{Comparison to other relatively high resolution late Maastrichtian records}

Other available late Maastrichtian temperature records with uncertainty estimates, and/or records with relatively high resolution, are the $\mathrm{TEX}_{86}$-based temperature records obtained from the New Jersey Shelf (Meirs Farm, inner shelf, Vellekoop et al., 2016) and from Argentina (Bajada del Jagüel, mid-shelf, Woelders et al., 2017). SSTs of these records are calculated using the $\mathrm{TEX}_{86}^{\mathrm{H}}$-equation by Kim et al. (2010) and are reported to have an uncertainty of $\pm 2.5^{\circ} \mathrm{C}$ (Kim et al., 2010). The high resolution temperature record from Walvis Ridge (ODP Site 1262, upper abyssal, Birch et al., 2016; Woelders et al., 2017) is based on bulk stable oxygen isotopes. The calibration uncertainty on these reconstructed temperatures, derived using the equation by Epstein et al. (1953), is $\pm 0.6^{\circ} \mathrm{C}$ (which seems to be an excessively small uncertainty). 
Bass River (New Jersey)
Meirs Farm

(New Jersey)
Walvis Ridge

(ODP Site 1262)
Bajada del Jagüel

(Argentina)
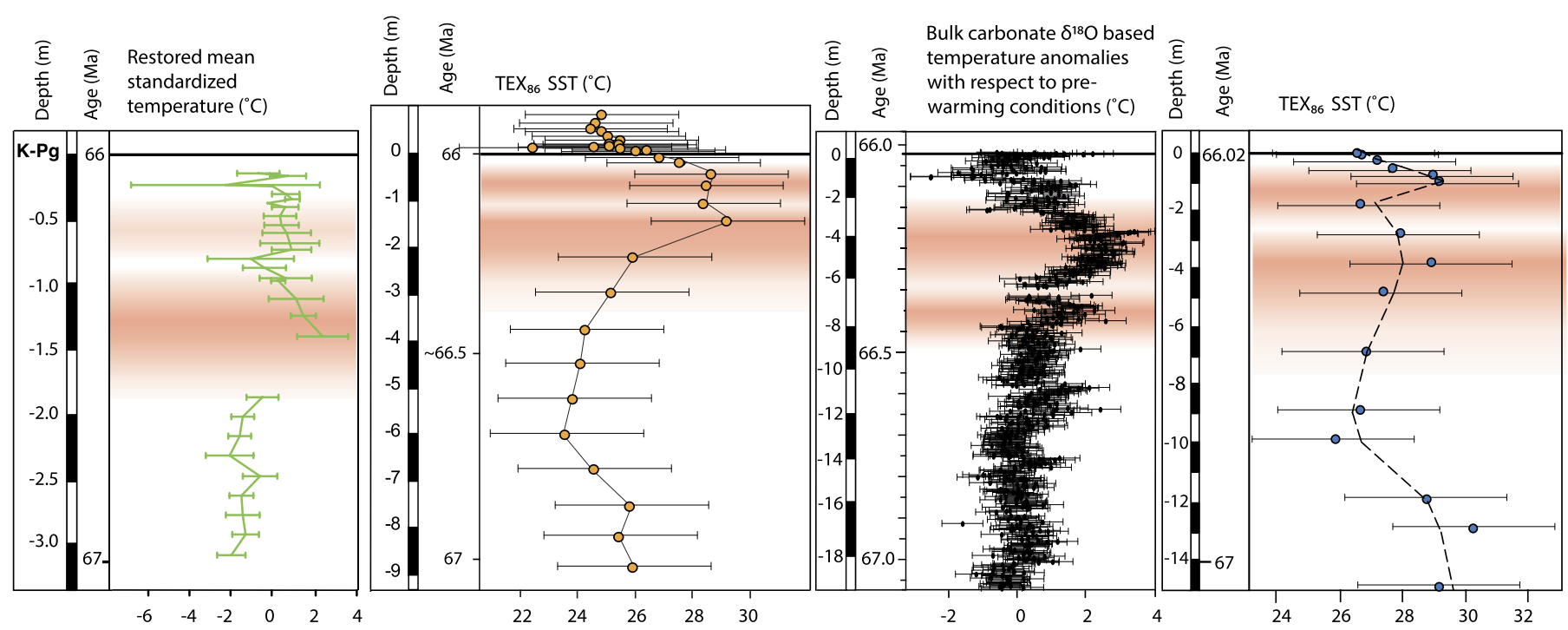

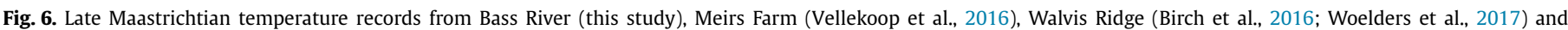
Bajada del Jagüel (Woelders et al., 2017).

These late Maastrichtian temperature records appear to be similar to those from the Bass River record: a relatively stable prewarming interval is followed by a warming interval that seemingly consists of several smaller warming events. Towards the $\mathrm{K}-\mathrm{Pg}$ boundary, a cooling is observed (Fig. 6). In addition, the estimated magnitude of the LMWE at Bass River can be compared to the magnitude of warming at other locations following the alternative approach described in section 4.1. The estimated magnitude of warming derived from the individual records from these different locations situated in different depositional environments is very similar (Fig. 7). Although these (single) proxy records often display a considerably larger uncertainty than our integrated reconstruction, these observations strongly suggest that the LMWE was a global phenomenon.

\section{Conclusions and recommendations}

This study provides different strategies to integrate multi-proxy temperature data. Our robust integrated approach results in an estimated $3.3 \pm 2.8^{\circ} \mathrm{C}$ warming during the late Maastrichtian at Bass River. A more pragmatic approach resulted in an estimation of late Maastrichtian warming of $3.9 \pm 1.1^{\circ} \mathrm{C}$. In this approach, anomalous records are excluded from the data integration and only the difference between the pre-warming interval and the highest temperature in the warming interval are compared regardless of when this warming occurred exactly. The error on the reconstructed magnitude of warming is the absolute minimum error as poorly constrained or unknown uncertainties cannot be fully propagated.

While our estimates are in agreement with other well-constrained, high resolution temperature records of the late Maastrichtian, our study also shows that combining multiple temperature reconstructions and their uncertainty estimates enables quantitative estimation of past climate change and can reduce uncertainty. It furthermore facilitates a qualitative assessment of the weight of evidence of individual proxy records. In order to be able to do this, however, it is necessary to accurately quantify uncertainties of individual temperature reconstructions.

Our approach of integrating multiple temperature records derived by different proxies relies on temperature trends rather than

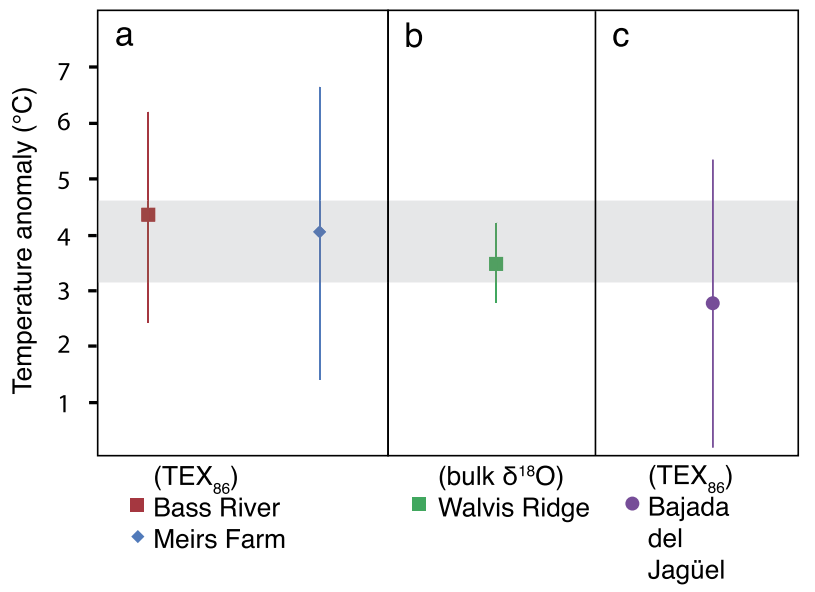

Fig. 7. (a) Magnitude of the LMWE estimated from TEX 86 -based temperature records from two locations at the New Jersey Shelf (Bass River, this study, and Meirs Farm, Vellekoop et al., 2016). The magnitude of the LMWE was estimated by comparing the weighted mean of the $\mathrm{TEX}_{86}$-based temperatures of the pre-warming interval with the highest temperature in the warming interval (alternative approach, see section 4.1). (b) Magnitude of the LMWE estimated from a bulk stable oxygen isotope based temperature record from ODP Site 1262 (Walvis Ridge) (Birch et

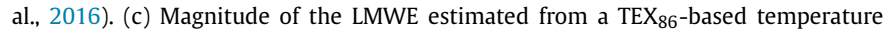
record from Bajada del Jagüel (Woelders et al., 2017). Light gray area: weighted mean average of the LMWE from benthic and planktic $\mathrm{Mg} / \mathrm{Ca}$, benthic $\delta^{18} \mathrm{O}$ and TEX $_{86}$-based temperature reconstructions from Bass River (this study).

on absolute temperature estimates, as temperature trends are more robust than absolute reconstructed paleotemperatures, especially in deep-time and over relatively short time intervals. We show that in using $\delta^{18} \mathrm{O}, \mathrm{Mg} / \mathrm{Ca}$ and $\mathrm{TEX}_{86}$ and present-day transfer functions to obtain temperature trends over relatively short time intervals in the late Cretaceous, differences in these parameters between the present-day and the late Cretaceous can be neglected. In line with this, calculated absolute temperatures in this study should primarily be regarded as an indication for potential absolute temperatures. Yet, it should be noted that rapidly changing $\delta^{18} \mathrm{O}_{\mathrm{sw}}, \mathrm{Mg} / \mathrm{Ca}_{\mathrm{sw}}$ and $\mathrm{pH}_{\mathrm{sw}}$ values within the short interval from which a trend is extracted, can, in fact, influence reconstructed absolute temperatures differently throughout this interval. Thereby, 
these unconstrained factors can also introduce unconstrained uncertainties on the relative temperature estimates.

The uncertainty quantifications in this study suggest that in order to improve multi-proxy based reconstructions of absolute temperatures, the uncertainties within temperature transfer functions must be properly estimated and reduced where possible. To be able to do so more effectively, the three sources of uncertainty as mentioned in the Introduction should all be addressed. Firstly, it is recommended that all studies reconstructing paleo-temperatures include raw measurement data with analytical errors (and replicate analyses if possible). Secondly, raw data on which current as well as future calibrations are based should be made available publicly. This allows calibrations to be improved as insights grow and it allows for the development of calibrations based on larger datasets than the original set. Finally, unknown and unquantified uncertainties that may influence reconstructed temperatures, such as atmospheric $\mathrm{CO}_{2}$ and local hydrological processes, need to be better constrained. This would make it possible to set up comprehensive error budgets, and greatly improve deep-time multi-proxy based temperature reconstructions.

\section{Authorship}

L.W. contributed to the conception and design of the study, acquired data, analyzed and interpreted the data and drafted the manuscript. J.V. contributed to the conception and design of the study, acquired data, analyzed and interpreted the data and drafted the manuscript. G.J.W. contributed to the conception and design of the study, analyzed and interpreted the data and revised the manuscript critically. L.d.N, G.J.R., F.P. and P.C. contributed to data acquisition and revised the manuscript critically. R.P.S. contributed to the conception and design of the study and revised the manuscript critically. All authors approve of this version to be submitted.

\section{Acknowledgements}

We would like to thank Wim Boer, Stef van Steenberghe and Niels de Winter for their laboratory assistance. We would like to thank Jessica Tierney, Marit Brommer, two anonymous reviewers and the editor for their valuable comments and suggestions, which greatly improved the manuscript. Funding of this project was provided by the Research Foundation Flanders (FWO) to R.P.S. and P.C. (G.0B85.13). NWO grant 834.11.006 enabled the purchase of the UHPLC-MS system used for GDGT analysis at Utrecht University. This research was partially funded by a NESSC Gravitation Grant (024.002.001) from the Dutch Ministry of Education, Culture and Science (OCW).

\section{Appendix A. Supplementary material}

Supplementary material related to this article can be found online at https://doi.org/10.1016/j.epsl.2018.08.010.

\section{References}

Abramovich, S., Keller, G., Stüben, D., Berner, Z., 2003. Characterization of late Campanian and Maastrichtian planktonic foraminiferal depth habitats and vital activities based on stable isotopes. Palaeogeogr. Palaeoclimatol. Palaeoecol. 202, 1-29. https://doi.org/10.1016/S0031-0182(03)00572-8.

Anand, P., Elderfield, H., Conte, M.H., 2003. Calibration of $\mathrm{Mg} / \mathrm{Ca}$ thermometry in planktonic foraminifera from a sediment trap time series. Paleoceanography 18 1050. https://doi.org/10.1029/2002PA000846.

Barnet, J.S.K., Littler, K., Kroon, D., Leng, M.J., Westerhold, T., Röhl, U., Zachos, J.C., 2017. A new high-resolution chronology for the late Maastrichtian warming event: establishing robust temporal links with the onset of Deccan volcanism. Geology 46, 147-150
Barrera, E., Savin, S.M., 1999. Evolution of late Campanian-Maastrichtian marine climates and oceans. In: Barrera, E., Johnson, E. (Eds.), Evolution of the Cretaceous Ocean-Climate System. In: Geological Society of America Special Paper, vol. 332, pp. 245-282.

Bemis, B.E., Spero, H.J., Bijma, J., Lea, D.W., 1998. Reevaluation of the oxygen isotopic composition of planktonic foraminifera: experimental results and revised paleotemperature equations. Paleoceanography 13, 150-160.

Birch, H.S., Coxall, H.K., Pearson, P.N., Kroon, D., Schmidt, D.N., 2016. Partial collapse of the marine carbon pump after the Cretaceous-Paleogene boundary. Geology 44, 287-290. https://doi.org/10.1130/G37581.1.

Bloemsma, M.R., Zabel, M., Stuut, J.B.W., Tjallingii, R., Collins, J.A., Weltje, G.J., 2012. Modelling the joint variability of grain size and chemical composition in sediments. Sediment. Geol. 280, 135-148. https://doi.org/10.1016/j.sedgeo.2012.04. 009.

Chenet, A.-L., Quidelleur, X., Fluteau, F., Courtillot, V., Bajpai, S., 2007. ${ }^{40} \mathrm{~K}-{ }^{40} \mathrm{Ar}$ dating of the Main Deccan large igneous province: further evidence of KTB age and short duration. Earth Planet. Sci. Lett. 263, 1-15. https://doi.org/10.1016/j.epsl. 2007.07.011.

Cramwinckel, M.J., Huber, M., Kocken, I.J., Agnini, C., Bijl, P.K., Bohaty, S.M., Frieling, J., Goldner, A., Hilgen, F.J., Kip, E.L., Peterse, F., van der Ploeg, R., Röhl, U., Schouten, S., Sluijs, A., 2018. Synchronous tropical and polar temperature evolution in the Eocene. Nature 559, 382-386. https://doi.org/10.1038/s41586-0180272-2.

D'Hondt, S., Zachos, J.C., 1998. Cretaceous foraminifera and the evolutionary history of planktic photosymbiosis. Paleobiology 24, 512-523.

Elling, F.J., Könneke, M., Mußmann, M., Greve, A., Hinrichs, K.-U., 2015. Influence of temperature, $\mathrm{pH}$, and salinity on membrane lipid composition and $\mathrm{TEX}_{86}$ of marine planktonic thaumarchaeal isolates. Geochim. Cosmochim. Acta 171, 238-255.

Epstein, S., Buchsbaum, H., Lowenstam, H.A., Urey, H.C., 1953. Variation of $\mathrm{O}^{18}$ content of waters from natural sources. Bull. Geol. Soc. Am. 64, 1315-1326.

Esmeray-Senlet, S., Wright, J.D., Olsson, R.K., Miller, K.G., Browning, J.V., Quan, T.M., 2015. Evidence for reduced export productivity following the Cretaceous/Paleogene mass extinction. Paleoceanography 30, 718-738. https://doi.org/10.1002/ 2014 PA002724.

Fraass, A.J., Lowery, C.M., 2017. Defining uncertainty and error in planktic foraminiferal isotope measurements. Paleoceanography 32, 104-122. https:// doi.org/10.1002/2016PA003035.

Henehan, M.J., Hull, P.M., Penman, D.E., Rae, J.W.B., Schmidt, D.N., 2016. Biogeochemical significance of pelagic ecosystem function: an end-Cretaceous case study. Philos. Trans. R. Soc. B 371. https://doi.org/10.1098/rstb.2015.0510.

Hopmans, E.C., Schouten, S., Sinninghe Damsté, J.S., 2016. The effect of improved chromatography on GDGT-based palaeoproxies. Org. Geochem. 93, 1-6. https:// doi.org/10.1016/j.orggeochem.2015.12.006.

Kim, J.H., van der Meer, J., Schouten, S., Helmke, P., Willmott, V., Sangiorgi, F., Koc, N., Hopmans, E.C., Sinninghe Damsté, J.S., 2010. New indices and calibrations derived from the distribution of crenarchaeal isoprenoid tetraether lipids: implications for past sea surface temperature reconstructions. Geochim. Cosmochim. Acta 74, 4639-4654. https://doi.org/10.1016/j.gca.2010.05.027.

Kısakürek, B., Eisenhauer, A., Böhm, F., Garbe-Schönberg, D., Erez, J., 2008. Controls on shell $\mathrm{Mg} / \mathrm{Ca}$ and $\mathrm{Sr} / \mathrm{Ca}$ in cultured planktonic foraminiferan Globigerinoides ruber (white). Earth Planet. Sci. Lett. 273, 260-269. https://doi.org/10.1016/j. epsl.2008.06.026.

Lawrence, K.T., Woodard, S.C., 2017. Past sea surface temperatures as measured by different proxies - a cautionary tale from the Late Pliocene. Paleoceanography. https://doi.org/10.1002/2017PA003101.

Lea, D.W., Mashiotta, T.A., Spero, H.J., 1999. Controls on magnesium and strontium uptake in planktonic foraminifera determined by live culturing. Geochim. Cosmochim. Acta 63, 2369-2379.

Lear, C.H., Rosenthal, Y., Slowey, N., 2002. Benthic foraminiferal Mg/Capaleothermometry: a revised core-top calibration. Geochim. Cosmochim. Acta 66, 3375-3387.

Li, L., Keller, G., 1998. Abrupt deep-sea warming at the end of the Cretaceous. Geology 26, 995-998.

Marchitto, T.M., Curry, W.B., Lynch-Stieglitz, J., Bryan, S.P., Cobb, K.M., Lund, D.C., 2014. Improved oxygen isotope temperature calibrations for cosmopolitan benthic foraminifera. Geochim. Cosmochim. Acta 130, 1-11.

Martin, P.A., Lea, D.W., Rosenthal, Y., Shackleton, N.J., Sarnthein, M., Papenfuss, T., 2002. Quaternary deep sea temperature histories derived from benthic foraminiferal Mg/Ca. Earth Planet. Sci. Lett. 198, 193-209.

Miller, K.G., Sugarman, P.J., Browning, J.V., Olsson, R.K., Pekar, S.F., Reilly, T.J., Cramer, B.S., Aubry, M.-P., Lawrence, R.P., Curran, J., Stewart, M., Metzger, J.M., Uptegrove, J., Bukry, D., Burckle, L.H., Wright, J.D., Feigenson, M.D., Brenner, G.J., Dalton, R.F., 1998. Bass River site. In: Miller, K.G., Sugarman, P.J., Browning, J.V., Olsson, R.K., Pekar, S.F., Reilly, T.J., Cramer, B.S., Aubry, M.-P., Lawrence, R.P., Curran, J., Stewart, M., Metzger, J.M., Uptegrove, J., Bukry, D., Burckle, L.H., Wright, J.D., Feigenson, M.D., Brenner, G.J., Dalton, R.F. (Eds.), Proceedings of the Ocean Drilling Program, Initial Reports, 174AX. College Station, pp. 5-43.

Miller, K.G., Wright, J.D., Browning, J.V., 2005. Visions of ice sheets in a greenhouse world. Mar. Geol. 217, 215-231. 
Nordt, L., Atchley, S., Dworkin, S., 2003. Terrestrial evidence for two greenhouse events in the latest Cretaceous. GSA Today 13, 4-9.

Olsson, R.K., Miller, K.G., Browning, J.V., Habib, D., Sugarman, P.J., 1997. Ejecta layer at the Cretaceous-Tertiary boundary, Bass River, New Jersey (Ocean Drilling Program Leg 174AX). Geology 25, 759-762.

Olsson, R.K., Miller, K.G., Browning, J.V., Wright, J.D., Cramer, B.S., 2002. Sequence stratigraphy and sea-level change across the Cretaceous-Tertiary boundary on the New Jersey passive margin. In: Koeberl, C., Macleod, K.G. (Eds.), Catastrophic Events and Mass Extinctions: Impacts and Beyond. In: Spec. Pap., Geol. Soc. Am., vol. 356, pp. 97-108.

Otto-Bliesner, B.L., Jahn, A., Feng, R., Brady, E.C., Hu, A., Löfverström, M., 2017. Amplified North Atlantic warming in the late Pliocene by changes in Arctic gateways. Geophys. Res. Lett. 44, 957-964.

Pearson, P.N., Ditchfield, P.W., Singano, J., Harcourt-Brown, K.G., Nicholas, C.J., Olsson, R.K., Shackleton, N.J., Hall, M.A., 2001. Warm tropical sea surface temperatures in the late Cretaceous and Eocene epochs. Nature 413, 481-487. https://doi.org/ $10.1038 / 35097000$.

Petersen, S.V., Dutton, A., Lohmann, K.C., 2016. End-Cretaceous extinction in Antarctica linked to both Deccan volcanism and meteorite impact via climate change. Nat. Commun. 7, 12079.

Reichart, G.J., Jorissen, F., Anschutz, P., Mason, P.R.D., 2003. Single foraminiferal test chemistry records the marine environment. Geology 31, 355-358.

Russell, A.D., Hönish, B., Spero, H., Lea, D.W., 2004. Seawater carbonate chemistry, processes and elements during experiments with planktonic foraminifera Orbulina universa. Pangaea 68, 4347-4361.

Schoene, B., Samperton, K.M., Eddy, M.P., Keller, G., Adatte, T., Bowring, S.A., Khadri, S.F.R., Gertsch, B., 2015. U-Pb geochronology of the Deccan Traps and relation to the end-Cretaceous mass extinction. Science 347, 9-12.

Schouten, S., Hopmans, E.C., Sinninghe Damsté, J.S., 2013. The organic geochemistry of glycerol dialkyl glycerol tetraether lipids: a review. Org. Geochem. 54, 19-61.

Shackleton, N.J., Kennett, J.P., 1975. Paleotemperature history of the Cenozoic and the initiation of Antarctic glaciation: oxygen and carbon isotope analyses in DSDP Sites 277, 279, and 281. Initial Rep. Deep Sea Drill. Proj. 29, 743-755.

Sloan, L.C., Huber, M., Crowley, T.J., Sewall, J.O., Baum, S., 2001. Effect of sea surface temperature configuration on model simulations of "equable" climate in the early Eocene. Palaeogeogr. Palaeoclimatol. Palaeoecol. 167, 321-335. https:// doi.org/10.1016/S0031-0182(00)00245-5.

Stanley, S.M., Hardie, L., 1998. Secular oscillations in the carbonate mineralogy of reef-building and sediment-producing organisms driven by tectonically forced shifts in seawater chemistry. Palaeogeogr. Palaeoclimatol. Palaeoecol. 144, 3-19.
Thibault, N., Harlou, R., Schovsbo, N.H., Stemmerik, L., Surlyk, F., 2016. Late Cretaceous (late Campanian-Maastrichtian) sea-surface temperature record of the Boreal Chalk Sea. Clim. Past 12, 1-10. https://doi.org/10.5194/cp-12-1-2016.

Tierney, J.E., Tingley, M.P., 2014. A Bayesian, spatially-varying calibration model for the TEX $_{86}$ proxy. Geochim. Cosmochim. Acta 127, 83-106. https://doi.org/10. 1016/j.gca.2013.11.026.

Tobin, T.S., Ward, P.D., Steig, E.J., Olivero, E.B., Hilburn, I.A., Mitchell, R.N., Diamond, M.R., Raub, T.D., Kirschvink, J.L., 2012. Extinction patterns, $\delta^{18} \mathrm{O}$ trends, and magnetostratigraphy from a southern high-latitude CretaceousPaleogene section: links with Deccan volcanism. Palaeogeogr. Palaeoclimatol. Palaeoecol. 350-352, 180-188. https://doi.org/10.1016/j.palaeo.2012.06.029.

Tobin, T.S., Wilson, G.P., Eiler, J.M., Hartman, J.H., 2014. Environmental change across a terrestrial Cretaceous-Paleogene boundary section in eastern Montana, USA, constrained by carbonate clumped isotope paleothermometry. Geology 42 351-354. https://doi.org/10.1130/G35262.1.

Vellekoop, J., Esmeray-Senlet, S., Miller, K.G., Browning, J.V., Sluijs, A., van de Schootbrugge, B., Sinninghe Damsté, J.S., Brinkhuis, H., 2016. Evidence for CretaceousPaleogene boundary bolide "impact winter" conditions from New Jersey, USA Geology 44, 619-622. https://doi.org/10.1130/G37961.1.

Westerhold, T., Röhl, U., Donner, B., McCarren, H.K., Zachos, J.C., 2011. A complete high-resolution Paleocene benthic stable isotope record for the centra Pacific (ODP Site 1209). Paleoceanography 26, PA2216. https://doi.org/10.1029/ 2010PA002092.

Wilf, P., Johnson, K.R., Huber, B.T., 2003. Correlated terrestrial and marine evidence for global climate changes before mass extinction at the Cretaceous-Paleogene boundary. Proc. Natl. Acad. Sci. USA 100, 599-604. https://doi.org/10.1073/pnas. 0234701100.

Woelders, L., Vellekoop, J., Kroon, D., Smit, J., Casadio, S., Prámparo, M.B., DinarèsTurell, J., Peterse, F., Sluijs, A., Speijer, R.P., 2017. Latest Cretaceous climatic and environmental change in the South Atlantic region. Paleoceanography. https:// doi.org/10.1002/2016PA003007.

Zachos, J.C., Schouten, S., Bohaty, S., Quattlebaum, T., Sluijs, A., Brinkhuis, H., Gibbs, S.J., Bralower, T.J., 2006. Extreme warming of mid-latitude coastal ocean during the Paleocene-Eocene Thermal Maximum: inferences from TEX 86 and isotope data. Geology 34, 737-740. https://doi.org/10.1130/G22522.1.

Zeebe, R.E., 2001. Seawater pH and isotopic paleotemperatures of Cretaceous oceans. Palaeogeogr. Palaeoclimatol. Palaeoecol. 170, 49-57. 